My response to the authors' striking claim that they propose a new model (even if only 'an outline sketch of a potential model') is: what model? Unfortunately, careful reading of the paper in search of this model resulted in little that is new and certainly nothing approaching a testable hypothesis.

Is it a new model to state that the environment affects the configuration of the self and that this can somehow lead to psychosis? The authors cite the example of migration and its association with increased risk of psychosis to illustrate their point, but it does not seem that they have anything new to say about this fascinating area.

The authors call for greater rigour in future conceptual models that integrate the biological and the social in the aetiology of psychosis. It is, therefore, doubly surprising that they advocate the integration of hermeneutically oriented social sciences into such future models. Given that hermeneutics is disconnected from the rigours of the laws of causation that govern the material world, one wonders how this would reduce the 'vagueness' that the authors warn us against. It is also of interest that the two other concepts central to the authors' model are the 'self' - a concept that has numerous competing definitions (one article cited 21 competing concepts of the self; see Zahavi, 2003) - and 'social capital', which has no operational definition (see McKenzie et al, 2002). It seems to me that the authors should have followed their own admonition against vagueness or else produced their own clear definitions of these concepts.

Also, the authors commit an elementary error by confusing the concept of 'biological' with 'genetic' or 'genomic' in their critique of current theories on schizophrenia, citing the work of Eisenberg (2004). When we consider the role of a given environmental factor in shaping a particular trait, we are most certainly dealing with a biological process. Can we discuss the effect of sunlight on tanning of the skin without considering melanocytes and melanin (see Gaulin \& McBurney, 2001)? Similarly, if the human brain/mind has the propensity, under certain environmental conditions and given a particular genetic make-up and early-life experience, to produce the clinical picture we call psychosis, this cannot be understood outside of biology. Phenotypes, we should remember, are not simply the obligate expression of genes but the complex outcome of the interaction of the genome with the environment. In other words, the identification of an environmental risk factor for a particular disorder is not the end of the story. To achieve a real understanding of how the phenotypic trait was shaped, we still need to understand the intra-organismic process that led to the said trait.

Eisenberg, L. (2004) Social psychiatry and the human genome: contextualising heritability. British Journal of Psychiatry, 184, I01-103.

Gaulin, S. J. C. \& McBurney, D. H. (200I) Psychology: An Evolutionary Approach. New Jersey: Prentice Hall.

Harland, R., Morgan, C. \& Hutchinson, G. (2004)

Phenomenology, science and the anthropology of the self: a new model for the aetiology of psychosis. British Journal of Psychiatry, 185, 361-362.

McKenzie, K., Whitley, R. \& Weich, S. (2002) Social capital and mental health. British journal of Psychiatry, 18I, 280-283.

Zahavi, D. (2003) Phenomenology of self. In The Self in Neuroscience and Psychiatry (eds T. Kircher \& A. David) pp. 56-75. Cambridge: Cambridge University Press.

R. Abed Rotherham District General Hospital, Moorgate Road, Rotherham S60 2UD, UK. E-mail: abedrt@btinternet.com

Authors' reply: In suggesting that the environment acts to produce biologically based phenotypes depending on genetic propensity, through 'intra-organismic' processes, this letter points to one mantra of modern psychiatry. But in looking for how our editorial contributes to the incremental nature of this important science it misunderstands our intent.

By 'a new model' we are describing an alternative way of seeing the problem, as opposed to the box and line model we have become more familiar with when considering a novel testable hypothesis. Phenomenology, conceived by Husserl, developed through Heidegger, Ricoeur and others, is notoriously difficult. On these terms there may be those who feel that what we have attempted is misconceived. However, it is a tradition that influenced many of the early scientific thinkers in our field, including Jaspers, Schneider, Minkowski and Lewis, and it continues to influence today (e.g. Cutting, 1997; Sass, 2004; Stanghellini, 2004).

To precis Dan Zahavi (2003: p. 59) we cannot ask what it is like to be a bar of soap or a rock. However, we can ask what it is like to be a mouse, a human or, indeed, to experience schizophrenia. This 'what it is like' has an internal structure that phenomenology attempts to capture. Likewise, in our editorial we suggest that migration can provoke changes in 'what it is like to be' on a similar level and that the field of anthropology (which draws on phenomenology) offers insights here. We then link these changes to the increased rates of psychotic illness in some groups and suggest that this fits well with the current psychiatric thesis that the brain is the product of its own historical trajectory.

We remain open to whether biological or environmental correlates with identified phenomenological structures can meaningfully be found. But a reinvigoration of phenomenology is perhaps just what psychiatry needs at this time. We would do well to bring to mind that despite our best efforts we have yet to find aetiological factors in environmental or biological terms that take us beyond the group effect to the individual.

Above all the purpose of writing the editorial was to stimulate debate.

Cutting, J. (1997) Principles of Psychopathology. Oxford: Oxford University Press.

Sass, L. (2004) 'Negative symptoms', common sense and cultural disembedding in the modern age. In Schizophrenia, Culture, and Subjectivity (eds J. Hunter Jenkins \& R. J. Barrett), pp. 303-328. New York: Cambridge University Press.

Stanghellini, G. (2004) Disembodied Spirits and Deanimated Bodies. Oxford: Oxford University Press.

Zahavi, D. (2003) Phenomenology of the self. In The Self in Neuroscience and Psychiatry (edsT. Kircher \& A. David), pp. 56-75. Cambridge: Cambridge University Press.

R. Harland, C. Morgan Division of

Psychological Medicine, Institute of Psychiatry, London, UK. E-mail: r.harland@iop.kcl.ac.uk

G. Hutchinson The University of the West Indies, Department of Psychiatry, Mount Hope, Trinidad

\section{Personality and attachment in adolescence}

It was encouraging to see the study by Westen et al (2005) published in a mainstream journal such as the British Journal of Psychiatry. For a variety of reasons, there is a reluctance among many British adolescent mental health clinicians to diagnose personality disorders in their patients, despite the clear presence often of the requisite diagnostic features. This study shows that personality disorders in adolescents can be validly diagnosed, whether using an established framework such as the DSM-IV or a new, empirically derived taxonomy. 
I was struck by the extent to which certain factors derived from the Q-factor analysis appear to map onto current conceptualisation of attachment categories, a point borne out partially by the same research group (Nakash-Eisikovits et al, 2002) using Bartholomew's attachment classification (Bartholomew \& Horowitz, 1991). Specifically, the 'psychological health' factor shows strong correspondence to features of a secure internal working model, while the 'histrionic sexualisation' and 'emotional dysregulation' factors contain items integral to the conceptualisation of ambivalent/preoccupied attachment. It is interesting that in their 2002 study, the group found that attachment avoidance was correlated with their 'avoidant' Q-factor but not with DSM-IV avoidant personality disorder; on this basis, they questioned the prevailing conceptualisation of avoidant personality disorder. It is unclear how attachment disorganisation is related to the SWAP-200-A factors, as it is still uncertain the extent to which Bartholomew's 'fearful' category corresponds to disorganised/unresolved attachment.

Therefore, it is perhaps logical to hypothesise that some personality trait constellations (the most maladaptive of which may constitute personality disorders) are indeed disorders of attachment. This hypothesis, which is supported theoretically (Nakash-Eisikovits et al, 2002) and which makes intuitive sense to many adolescent mental health professionals, needs to be tested with longitudinal research. In addition to other empirical work, the above research shows the continuing clinical importance of attachment theory. However, there is still no easily administered validated measure of adolescent attachment in widespread clinical use currently in the UK. Surely, this is a deficit that needs to be addressed.

Bartholomew, K. \& Horowitz, L. M. (1991) Attachment styles among young adults: a test of a fourcategory model. Journal of Personality and Social Psychology, 61, 226-244.

Nakash-Eisikovits, O., Dutra, L. \& Westen, D. (2002) Relationship between attachment patterns and personality pathology in adolescents. Journal of the American Academy of Child and Adolescent Psychiatry, 41 IIII-II23.

Westen, D., Dutra, L. \& Shelder, J. (2005) Assessing adolescent personality pathology. British Journal of Psychiatry, 186, 227-238.

K. Ma Parkview Clinic, 60 Queensbridge Road, Moseley, Birmingham BI3 8QE, UK.

E-mail: kenkma@yahoo.co.uk

\section{Dementia prevalence}

Shaji et al (2005) have estimated the prevalence of dementia in an urban population in Kerala, India and have provided a glimpse into the various factors associated with dementia in their study. A few methodological issues of the study need further clarification.

Although a cut-off score of 23 on the Mini-Mental State Examination (MMSE) was used for all the participants, a different cut-off score would have been appropriate among those who were illiterate $(11.2 \%)$ as educational status has been shown to affect MMSE scores.

With no objective evidence to suggest hypertension in the participants other than the verbal account of the caregivers, the very high odds ratio for hypertension is misleading. Furthermore, with such a small number of individuals, the selection of the controls should have been more stringent. It would be advisable to take a larger number of controls for such a small sample of individuals with vascular dementia $(n=22)$.

Although age has been shown to be a risk factor for dementia in many studies, how this conclusion was reached in this study is not clear.

There is a discrepancy in the number of patients reported as receiving treatment for Alzheimer's dementia (21 out of 31 ) compared with the total number of individuals with Alzheimer's dementia detected in the study $(n=30)$.

Despite a few limitations, this study adds to the growing literature of the epidemiology of dementia in developing countries and would be helpful for healthcare planners for adequate resource allocation for preventive and curative services.

Table Involuntary placement in Italy

\begin{tabular}{|c|c|c|c|c|c|c|}
\hline \multirow[t]{3}{*}{ Year } & \multicolumn{6}{|c|}{ Involuntary placements } \\
\hline & \multicolumn{3}{|c|}{ Lombardy' } & \multicolumn{3}{|c|}{ Italy ${ }^{2}$} \\
\hline & $n$ & $\begin{array}{l}\text { Percentage of all } \\
\text { in-patient episodes }\end{array}$ & $\begin{array}{l}\text { Per } 100000 \\
\text { population }\end{array}$ & $n$ & $\begin{array}{l}\text { Percentage of all } \\
\text { in-patient episodes }\end{array}$ & $\begin{array}{c}\text { Per } 100000 \\
\text { population }\end{array}$ \\
\hline 1996 & 2832 & 12.3 & 37 & 14882 & 10.9 & 26 \\
\hline 1997 & 2818 & 11.6 & 37 & 15048 & II & 26 \\
\hline 1998 & 2803 & 12.1 & 36 & & & \\
\hline 1999 & 2792 & 12.6 & 36 & & & \\
\hline 2000 & 2794 & 11.8 & 35 & & & \\
\hline 2001 & 2487 & 10.8 & 31 & & & \\
\hline
\end{tabular}

I. Source: Regione Lombardia Sanità, I Servizi Psichiatrici della Regione Lombardia, anni 1996-200I

2. Source: Istituto Nazionale di Statistica, Annuario Statistiche della Sanità, anni 1996 e 1997.
Verghese, A. (2005) Prevalence

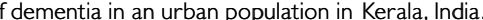
British Journal of Psychiatry, 186, 136-140.

S.T.Varghese All India Institute of Medical

Sciences, New Delhi II0 029, India.

E-mail: sunny_tv@rediffmail.com

\section{Involuntary placement in Italy}

Salize \& Dressing (2004) show figures for various indicators for involuntary placements in psychiatric facilities in the European Union countries. According to the authors, Italy was unable to provide nationwide data from the 1990s. Therefore, in Table 1 they showed data from the Lombardy region, concerning only the percentage of in-patient episodes that were involuntary placements for an 'unknown year'. Data from Lombardy on number and rate of involuntary placements per 100000 population are indicated as 'not available'

Actually, nationwide data have been published up to 1997, and data from the Lombardy region are available for the period 1995-2001 (see Table). The Italian data can be found on the website of the National Institute of Statistics (http://www.istat.it/Societ-/Sanita-e-p/ Storico) and those of Lombardy on the website of the Regional Directorate of Health (http://www.sanita.regione. lombardia.it/documenti).

Also, Salize \& Dressing report a rate of 11 involuntary placements per 100000 for France. This is not correct, as can be seen looking at absolute numbers of 61063 involuntary admissions in France. Given the French population of about 59.3 